\title{
A UNIVERSIDADE PÚBLICA PÓS-PANDEMIA DA COVID-19: uma nova instituição para um novo tempo
}

\author{
Maria das Graças Gonçalves Vieira Guerra \\ Universidade Federal da Paraíba - UFPB, Brasil \\ Lourdes Maria Rodrigues Cavalcanti \\ Universidade Federal da Paraíba - UFPB, Brasil
}

\begin{abstract}
Resumo
O objetivo deste artigo é refletir sobre o modelo de universidade pública pós-pandemia da COVID19, a partir dos dados disponibilizados pelo Portal do Ministério da Educação, no site portal.mec.gov.br/coronavirus/, referentes à situação das atividades nas universidades federais, no Brasil, após a emissão da Portaria MEC n 343, de 17 de março de 2020. Utilizou-se uma metodologia de caráter exploratório, com abordagem qualitativa e estratégia bibliográficodocumental. Nos primeiros meses da pandemia, constatou-se que $80 \%$ das universidades federais não aderiram ao ensino remoto, deixando um contingente de quase um milhão de estudantes sem atividades, de forma que o perfil de universidade pública que emergiu dos dados trouxe à tona a necessidade de uma mudança no modelo institucional e organizacional que atualmente acomoda a universidade. Impõe-se que a universidade se reinvente, que se transforme em uma nova instituição, dotada de modelos de gestão atuais, flexíveis e que favoreçam ajustes, posto que tais funcionalidades, são mais adequadas à dinâmica organizacional e à troca de conhecimentos característicos do século XXI. Só assim será capaz de se inserir no contexto resultante do período pós-pandemia da COVID-19.
\end{abstract}

Palavras-chave: Educação Superior; Portal MEC/Coronavírus; Pandemia; Universidade pública.

\begin{abstract}
The purpose of this article is to reflect on the post-pandemic public university model of COVID-19, based on data made available by the Ministry of Education Portal, on the portal.mec.gov.br/coronavirus/, concerning the situation of activities in federal universities, in Brazil, after the issuance of Ordinance MEC $\mathrm{n}^{\circ}$ 343, of March 17, 2020. An exploratory methodology was used, with a qualitative approach and bibliographic-documental strategy. In the first months of the pandemic, it was found that $80 \%$ of federal universities did not adhere to remote education, leaving a contingent of almost one million students without activities, so that the profile of the public university that emerged from the data brought to light the need for a change in the institutional model that currently accommodates the University. It is imperative that the university reinvent itself, that it becomes a new institution, endowed with current, flexible management models and that favor adjustments, since such functionalities are best suited to organizational dynamics and the exchange of knowledge characteristic of the 21 st century. Only then will it be able to insert itself in the context resulting from the post-pandemic period of COVID-19.
\end{abstract}

Keywords: Higher Education; MEC / Coronavirus Portal; Pandemic; Public University. 


\section{Introdução}

No início do mês de fevereiro de 2020, o mundo tomou conhecimento, estarrecido, da existência do vírus COVID-19, originário da cidade de Wuhan, na China, no mês de dezembro de 2019. Fato é que acabou se transformando em uma pandemia, a primeira calamidade do século XXI, afetando, em nível mundial, a economia, os sistemas de saúde e a vida das pessoas, em um contexto em que as Nações contabilizam os prejuízos econômicos e sociais, causados pelo COVID-19, cuja letalidade expôs a fragilidade da vida humana, alterando, em nível planetário, para sempre, as rotinas familiares, sanitárias, econômicas, educacionais e de deslocamento, sejam de que forma for.

No Brasil, percebe-se que falta um projeto de nação, e o planejamento governamental, em todas as esferas do poder público, deixa a desejar, quando existe. Em relação à educação, vários fatores contribuem para o agravamento da situação inédita e bastante complexa, notadamente, em relação às universidades federais (IFES), objeto desta pesquisa, pois constatou-se que, mesmo dispondo de uma ferramenta de planejamento institucional, em vigor há mais de quinze anos - que é o Plano de Desenvolvimento Institucional (PDI) - não foi detectada a existência de um plano de contingência que fosse capaz de lidar com a crise causada pela pandemia, nem nas universidades federais, nem no Ministério da Educação (MEC).

A partir do mês de março de 2020, o Estado brasileiro passou a estabelecer medidas, em relação ao sistema federal de ensino, tendo como ato primeiro, a emissão da Portaria MEC $\mathrm{n}^{\circ}$ 343, de 17 de março de 2020. Esquematizou-se no Quadro 1, as normativas emitidas pela União, com vistas ao enfrentamento da pandemia do COVID-19.

Quadro 1. Atos legais do Estado Brasileiro para o enfrentamento ao COVID-19

\begin{tabular}{|c|c|}
\hline ATO & EMENTA \\
\hline $\begin{array}{l}\text { Portaria } \mathbf{n}^{\mathbf{0}} \mathbf{1 8 8} \text {, de } \mathbf{0 3} \text { de fevereiro de } \\
\mathbf{2 0 2 0} \\
\text { Publicada no DOU de } 04 / 02 / 2020\end{array}$ & $\begin{array}{l}\text { Declara Emergência em Saúde Pública de importância Nacional } \\
\text { (ESPIN) em decorrência da Infecção Humana pelo novo Coronavirus } \\
(2019-\mathrm{nCoV}) \text {. }\end{array}$ \\
\hline $\begin{array}{l}\text { Lei } \mathbf{n}^{\mathbf{0}} \text { 13.979, de } 06 \text { de fevereiro de } \\
\mathbf{2 0 2 0} \\
\text { Publicada no DOU de } 07 / 02 / 2020\end{array}$ & $\begin{array}{l}\text { Dispõe sobre as medidas para enfrentamento da emergência de saúde } \\
\text { pública de importância internacional decorrente do Coronavírus } \\
\text { responsável pelo surto de } 2019 \text {. }\end{array}$ \\
\hline $\begin{array}{l}\text { Medida Provisória } \mathbf{n}^{0} \mathbf{9 2 4} \text {, de } 13 \text { de } \\
\text { março de } 2020 \\
\text { Publicada no DOU de } 13 / 03 / 2020- \\
\text { edição extra }\end{array}$ & $\begin{array}{l}\text { Abre crédito extraordinário, em favor dos Ministérios da Educação e } \\
\text { da Saúde, no valor de R } \$ 5.099 .795 .979,00 \text {, para os fins que especifica. }\end{array}$ \\
\hline $\begin{array}{l}\text { Portaria } \mathbf{n}^{\mathbf{0}} \mathbf{3 4 3} \text {, de } \mathbf{1 7} \text { de março de } \\
\mathbf{2 0 2 0} \\
\text { Publicada no DOU de } 18 / 03 / 2020\end{array}$ & $\begin{array}{l}\text { Dispõe sobre a substituição das aulas presenciais por aulas em meios } \\
\text { digitais enquanto durar a situação de pandemia do Novo Coronavírus } \\
\text { (COVID-19). }\end{array}$ \\
\hline $\begin{array}{l}\text { Portaria } \mathbf{n}^{\mathbf{0}} \mathbf{4 9 1} \text {, de } 19 \text { de março de } \\
\mathbf{2 0 2 0} \\
\text { Publicada no DOU de } 19 / 03 / 2020- \\
\text { edição extra C }\end{array}$ & $\begin{array}{l}\text { Estabelece medidas temporárias de prevenção ao contágio pelo Novo } \\
\text { Coronavírus (COVID-19) no âmbito do Ministério da Educação. }\end{array}$ \\
\hline
\end{tabular}




\begin{tabular}{|c|c|}
\hline $\begin{array}{l}\text { Decreto Legislativo } \mathbf{n}^{\mathbf{0}} \mathbf{6} \text {, de } 20 \text { de } \\
\text { março de } 2020 \\
\text { Publicado no DOU de } 20 / 03 / 2020\end{array}$ & $\begin{array}{l}\text { Reconhece, para os fins do art. } 65 \text { da Lei Complementar } n^{\circ} 101 \text {, de } 4 \\
\text { de maio de } 2000 \text {, a ocorrência do estado de calamidade pública, nos } \\
\text { termos da solicitação do Presidente da República, encaminhada por } \\
\text { meio da Mensagem } n^{\circ} 93 \text {, de } 18 \text { de março de } 2020 \text {. }\end{array}$ \\
\hline $\begin{array}{l}\text { Portaria } \mathbf{n}^{\mathbf{0}} \text { 454, de } 20 \text { de março de } \\
\mathbf{2 0 2 0} \\
\text { Publicada no DOU de } 20 / 03 / 2020 \text { - } \\
\text { edição extra-F }\end{array}$ & $\begin{array}{l}\text { Declara, em todo o território nacional, o estado de transmissão do } \\
\text { coronavírus (COVID-19). }\end{array}$ \\
\hline $\begin{array}{l}\text { Decreto } \mathbf{n}^{\mathbf{0}} \mathbf{1 0 . 2 8 2} \text {, de } 20 \text { de março de } \\
\mathbf{2 0 2 0} \\
\text { Publicado no DOU de } 20 / 03 / 2020- \\
\text { edição extra-G e } \\
\text { Republicado no DOU de } 21 / 03 / 2020- \\
\text { edição extra-H }\end{array}$ & $\begin{array}{l}\text { iro de } 2020, \text { para definir } \\
\text { s. }\end{array}$ \\
\hline $\begin{array}{l}\text { Resolução } \mathbf{n}^{\mathbf{0}} \mathbf{2 0} \text {, de } \mathbf{2 3} \text { de março de } \\
\mathbf{2 0 2 0} \\
\text { Publicada no DOU de } 25 / 03 / 2020\end{array}$ & $\begin{array}{l}\text { Calamidade } \\
\text {-19). }\end{array}$ \\
\hline $\begin{array}{l}\text { Decreto } \mathbf{n}^{\mathbf{0}} \mathbf{1 0 . 2 9 2} \text { de } \mathbf{2 5} \text { de março de } \\
\mathbf{2 0 2 0} \\
\text { Publicado no DOU de } 26 / 03 / 2020\end{array}$ & $\begin{array}{l}\text { o } \mathrm{n}^{\circ} 10.282 \text {, de } 20 \text { de março de } 2020 \text {, que regulamenta } \\
\text {, de } 6 \text { de fevereiro de } 2020 \text {, para definir os serviços } \\
\text { ividades essenciais. }\end{array}$ \\
\hline $\begin{array}{l}\text { Portaria } \mathbf{n}^{\mathbf{0}} \mathbf{1 1 7} \text {, de } \mathbf{2 5} \text { de março de } \\
\mathbf{2 0 2 0} \\
\text { Publicada no DOU de } 26 / 03 / 2020\end{array}$ & $\begin{array}{l}\text { do estado de calamidade pública pelo Decreto } \\
\text { de } 20 \text { de março de } 2020 \text {. }\end{array}$ \\
\hline $\begin{array}{l}\text { Medida Provisória no 941, de } 02 \text { de } \\
\text { abril de } 2020 \\
\text { Publicada no DOU de } 02 / 04 / 2020 \text { - } \\
\text { edição extra B }\end{array}$ & $\begin{array}{l}\text { Abre crédito extraordinário, em favor dos Ministérios da Educação, da } \\
\text { Saúde e da Cidadania, no valor de R\$2.113.789.466,00, para os fins } \\
\text { que especifica. }\end{array}$ \\
\hline $\begin{array}{l}\text { Medida Provisória } \mathbf{n}^{0} \text { 942, de } 02 \text { de } \\
\text { abril de } 2020 \\
\text { Publicada no DOU de } 02 / 04 / 2020- \\
\text { edição extra B }\end{array}$ & $\begin{array}{l}\text { Abre crédito extraordinário, em favor da Presidência da República e } \\
\text { dos Ministérios da Educação, da Justiça e Segurança Pública, e da } \\
\text { Mulher, da Família e dos Direitos Humanos, no valor de R\$ } \\
639.034 .512,00 \text {, para os fins que especifica. }\end{array}$ \\
\hline $\begin{array}{l}\text { Portaria } \mathbf{n}^{\circ} \mathbf{3 9 5} \text {, de } 15 \text { de abril de } 2020 \\
\text { Publicada no DOU de } 16 / 04 / 2020\end{array}$ & $\begin{array}{l}\text { Prorroga o prazo previsto no } \S 1^{\circ} \text { do art. } 1^{\circ} \text { da Portaria n }{ }^{\circ} 343 \text {, de } 17 \text { de } \\
\text { março de } 2020 \text {. }\end{array}$ \\
\hline - 473, de 12 de maio de 2020 & $1^{\circ}$ da P \\
\hline
\end{tabular}

Fonte: BRASIL, 2020.

A emissão da Portaria MEC nº 343, de 17 de março de 2020, foi um marco em relação à regulamentação de medidas direcionadas ao sistema federal de ensino, ao determinar que as aulas presenciais canceladas, por força das circunstâncias impostas pela pandemia, deveriam ser repostas, visando concluir o semestre letivo, através de ensino remoto ou ensino mediado pelas Tecnologias da Informação e Comunicação (TICs), à exceção dos cursos de medicina e daqueles que requerem práticas de estágios e de laboratórios, dos demais cursos.

Diante da gravidade provocada pela explosão do número de casos do COVID-19, o MEC emitiu mais duas portarias, prorrogando a excepcionalidade da oferta de aulas mediadas pelas TICs, pelas universidades federais, por mais trinta dias, sendo a última, a Portaria MEC $\mathrm{n}^{\circ}$ 
473, emitida em 12 de maio de 2020, portanto, forneceu suporte legal para a situação, até o dia 12 de junho de 2020. Essa prorrogação de prazo, a conta gotas, a cada trinta dias, converteu-se em mais um desafio às universidades federais, notadamente em relação à garantia de acesso e permanência.

Segundo Dourado $(2019$, p.13), o atual governo tem feito duras críticas às universidades públicas, através de questionamentos diversos relacionados às finalidades da educação escolar, concretizando tais questionamentos através da redução drástica de recursos financeiros destinados, inclusive, à educação superior, causando insegurança e vulnerabilidade em tais instituições. $O$ fato traz grande preocupação, pois o Estado precisa, urgentemente, ser assertivo, relegando as discussões ideológicas, para outro momento mais oportuno, pois

O momento demanda ação. Governos marcados por ideologias pró-mercado e anti-Estado, como Alemanha, Estados Unidos e Reino Unido, para citar alguns exemplos, estão atuando com larga margem financeira. Focam na manutenção da reprodução da vida social e, assim, na preservação de empregos, empreendimentos e rendas, percebendo que o problema central não é de restrição fiscal a priori do Estado, o que não existe quando se tem a possibilidade de emitir moeda e dívida. Mas, sim, de manutenção da ordem social (FERRARI; CUNHA; 2020).

Feitas estas considerações, estruturou-se a presente pesquisa, apresentando-se na Introdução, ora em curso, a esquematização das medidas tomadas pelo Estado, com vistas ao enfrentamento da pandemia causada pelo COVID-19, no tocante à educação superior. Depois, forneceu-se um panorama da situação de atividade das universidades federais, a partir da emissão da Portaria MEC n 343, de 17 de março de 2020 - que regulamentou a oferta de aulas utilizando meios digitais, enquanto durar a situação de excepcionalidade, causada pelo COVID-19 - tendo por base relatórios, bancos de dados, legislação e outras ferramentas disponibilizadas pelo Portal do MEC, de forma que esta investigação de cunho exploratório, utilizou uma estratégia documental, sendo que foi considerado, como amostra de dados, os registros disponíveis no <portal.mec.gov.br/coronavirus/>, que subsidiaram os argumentos que sustentam a presente pesquisa, restrita ao âmbito das universidades federais. Em seguida, foi traçado o perfil do cidadão brasileiro, em relação ao acesso à internet e às ferramentas tecnológicas, com base em alguns dados da última Pesquisa Nacional por Amostra de Domicílio (PNAD) relativa ao uso das Tecnologias de Informação e Comunicação, realizada pelo Instituto Brasileiro de Geografia e Estatística (IBGE), no $4^{\circ}$ trimestre do ano de 2018 e, por último, o resultado da presente investigação tomou a forma de reflexões e argumentos, a partir da análise dos dados pesquisados, ressaltando-se que o presente estudo tem a pretensão de chamar a atenção para o modelo de universidade pública que emergiu dos dados, uma vez que constatou-se que a pandemia precipitou, não só as discussões relacionadas ao ensino a distância, ao aprendizado remoto e ao uso das TICs, mas também colocou em evidência que o modelo de universidade atualmente vigente, baseado na 
cátedra, precisará se reinventar, para se adequar às novas exigências impostas pela excepcionalidade do COVID-19.

\section{Panorama de atividades das Universidades Federais na pandemia}

Inicialmente, segue um esquema, no Gráfico 1, contendo os dados relativos a que tipo de equipamento o brasileiro utiliza mais, para acessar a internet, em conformidade com a última PNAD, relativa ao $4^{\circ}$ trimestre do ano de 2018 , que é a mais recente, realizada pelo IBGE.

Gráfico 1. Acesso à internet, por tipo de equipamento, e por região geográfica de acordo com a PNAD Contínua do $4^{\circ}$ trimestre de 2018

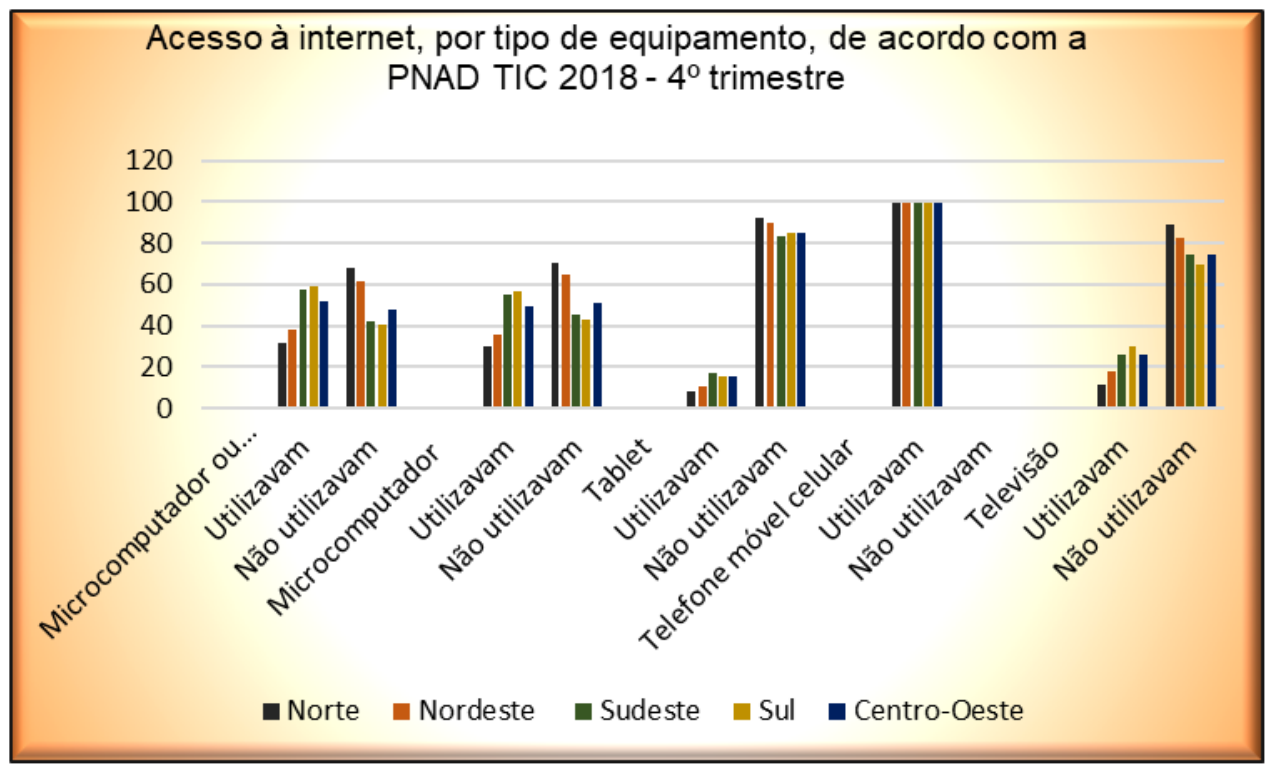

Fonte: Elaborado pelas autoras, baseadas em IBGE, 2018.

O equipamento mais usado para acessar a internet foi, portanto, o celular, encontrado em 99,2\% dos domicílios com serviço, sendo o microcomputador, o segundo mais usado em $48,1 \%$ desses lares. A Região Sudeste foi a que teve o maior índice de acesso à internet, em torno de $99,3 \%$, ou seja, praticamente, $100 \%$. A conexão por banda larga móvel mantém a liderança, em torno de $80,2 \%$, entretanto, o percentual de usuários da fixa é de $75,9 \%$, sendo que no período de 2016 a 2018, a pesquisa constatou a tendência de crescimento dos domicílios em que eram utilizados os dois tipos de banda larga ( $3 \mathrm{G}$ e $4 \mathrm{G})$, e leve retração do uso de somente um tipo de conexão.

De acordo com a referida PNAD o IBGE (2020), constatou que o principal motivo para não acessar a internet, é a falta de interesse, seguida de motivo causado porque nenhum morador sabia usar o serviço. Em relação à falta de interesse, os maiores percentuais 
concentram-se nas regiões Sudeste (42,0\%), Sul (43,0\%) e Centro-Oeste (36,3\%). Por outro lado, quando se trata de motivo referente a que nenhum morador sabe usar o serviço de internet, o menor percentual fica na região Norte, onde $15,1 \%$ não sabe usar o serviço, sendo esta a menor taxa em relação a esse índice. Nas demais regiões, o fato de não saber usar a internet, mantém-se em um patamar superior à $20 \%$ estando, entretanto, muito próximos os índices, nas demais regiões, acima dos $20 \%$ e menor que $30 \%$, conforme segue: Região Nordeste 23,2\% não sabem usar o serviço; Região Sudeste 26,4\% não sabem usar a internet; Região Sul 28,4\% e Região Centro-Oeste, 26,8\% não sabem usar o serviço de internet. Em outras palavras, a Região Nordeste é a que apresenta o menor índice dos que não sabem usar o serviço e a Região Sul é a que apresenta o maior percentual de usuários que não utilizam o serviço, porque não sabem fazê-lo, sendo em torno de $28,4 \%$.

Feitas estas considerações, para prestar contas das ações governamentais, de enfrentamento ao COVID-19, o MEC criou o <portal.mec.gov.br/coronavirus/>, transcorridos dois meses após o surgimento dos primeiros casos da pandemia, no Brasil, e de acordo com os dados disponibilizados, no mês de maio do ano de 2020, das 69 IFES, 8 estavam em atividades remotas, 6 com atividades parciais, e $55 \mathrm{com}$ as atividades suspensas, De um total de 1.123.691 discentes matriculados, 153.402 encontravam-se em atividades remotas, 99.899, em atividades parciais e 870.390, com as atividades acadêmicas suspensas. Tal panorama é apresentado no Gráfico 2.

Gráfico 2. Panorama Geral das atividades nas IFES, após a emissão da Portaria MEC nº 343/2020

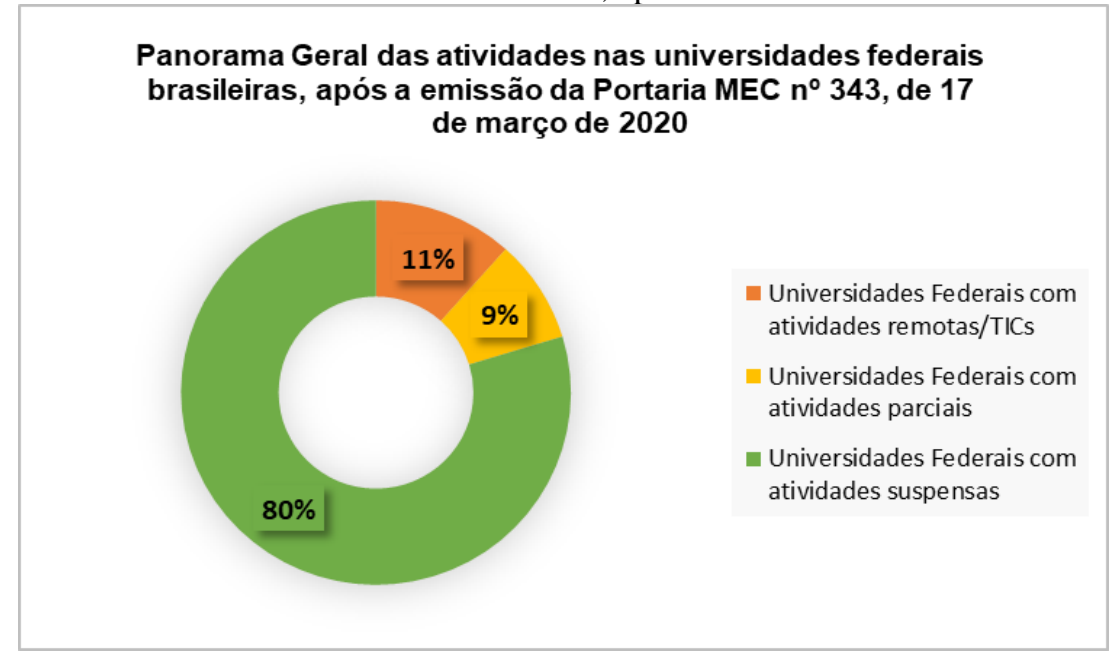

Fonte: Elaborado pelas autoras, 2020.

De um contingente de 69 universidades federais, apenas $20 \%$ estava funcionando, desenvolvendo suas atividades via remota ou em regime de atividades parciais, atendendo, desta forma, à apenas $22,5 \%$ do contingente de discentes matriculados, o que significou que cerca de $80 \%$ ficou fora das salas de aula. Esse foi um dado bastante preocupante, pois demonstrou que, naquele momento, as universidades federais não foram capazes de cumprir o seu papel básico de dar acesso universal àqueles que procuram um ensino superior de 
qualidade. E o que dizer do panorama das universidades federais que suspenderam suas atividades, por região geográfica? Vejamos o que nos mostra o Gráfico 3.

Gráfico 3. IFES que suspenderam suas atividades por força da Portaria MEC n 343/2020

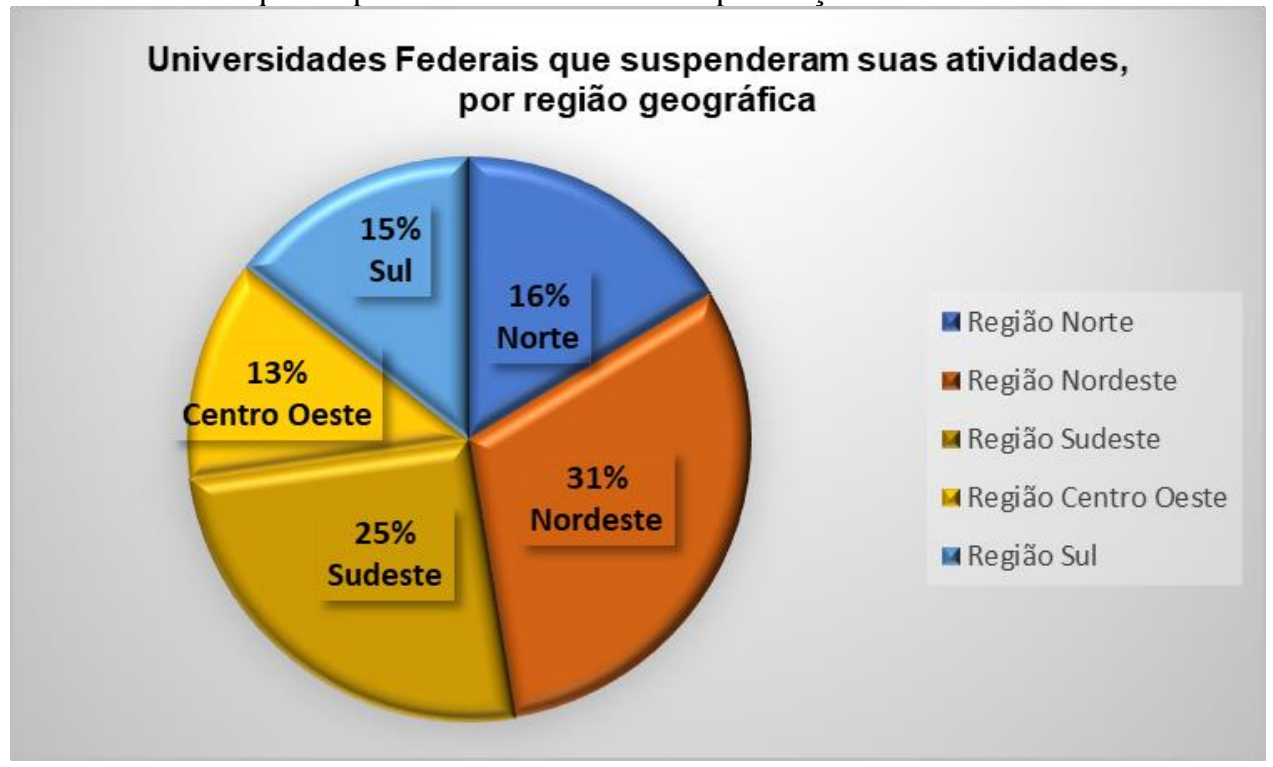

Fonte: Elaborado pelas autoras, baseadas em MEC, 2020.

A Região Nordeste, foi a que apresentou o maior índice de universidades federais com atividades suspensas, em torno de $31 \%$, estando, em segundo lugar, para nossa surpresa, a Região Sudeste, respondendo por $25 \%$ do total nacional de universidades federais com as atividades paralisadas. As regiões Sul, Norte e Centro Oeste, apresentaram percentuais muito próximos, cujos índices são, separadamente, cada qual, a metade dos índices apresentados pelas regiões Nordeste e Sudeste. Disto, depreende-se que as universidades federais das Regiões Centro Oeste, Sul e Norte, tiveram maiores índices de adesão ao ensino remoto ou às atividades em regime parcial, do que aquelas localizadas nas Regiões Nordeste e Sudeste. Os dados da PNAD TIC de 2018, do IBGE, apontam que a Região Sudeste tem um percentual de $84,8 \%$ de acesso à internet e às tecnologias, maior do que a média nacional, que é de 79,1\%. Apesar disso, as universidades da Região Sudeste têm o segundo maior percentual de atividades suspensas, o que, dado o perfil que emergiu da PNAD 2018 do IBGE, é uma grande contradição, pois trata-se da região mais rica do país, que apresenta o segundo maior Índice de Desenvolvimento Humano (IDH), em torno de 0,766 de acordo com o IPEA (2016). Regionalmente há discrepâncias, mas em todas elas o percentual de estudantes inseridos nesta faixa de renda está acima de $60 \%$ da população-alvo. O Nordeste era, em 2014, a região com o maior percentual de estudantes na faixa de renda mensal familiar per capita de "Até 1 e meio Salário Mínimo (SM)", tendo sido superado, em 2018, pelo Norte. Por seu turno, o Centro-Oeste, que em 2014 concentrava o menor percentual, foi ultrapassado pelo Sul. A 
renda mensal per capita média do grupo familiar da população-alvo é de $\mathrm{R} \$ 1.328,08$. (ANDIFES, 2018, p. 211).

A seguir, o Gráfico 4 apresenta os valores percentuais de utilização de internet, em nosso país, em conformidade com a PNAD TIC do $4^{\circ}$ trimestre de 2018 , realizada pelo IBGE.

Gráfico 4. Valores percentuais de utilização de internet, em domicílios particulares permanentes, por região $4^{\circ}$ trimestre de 2018

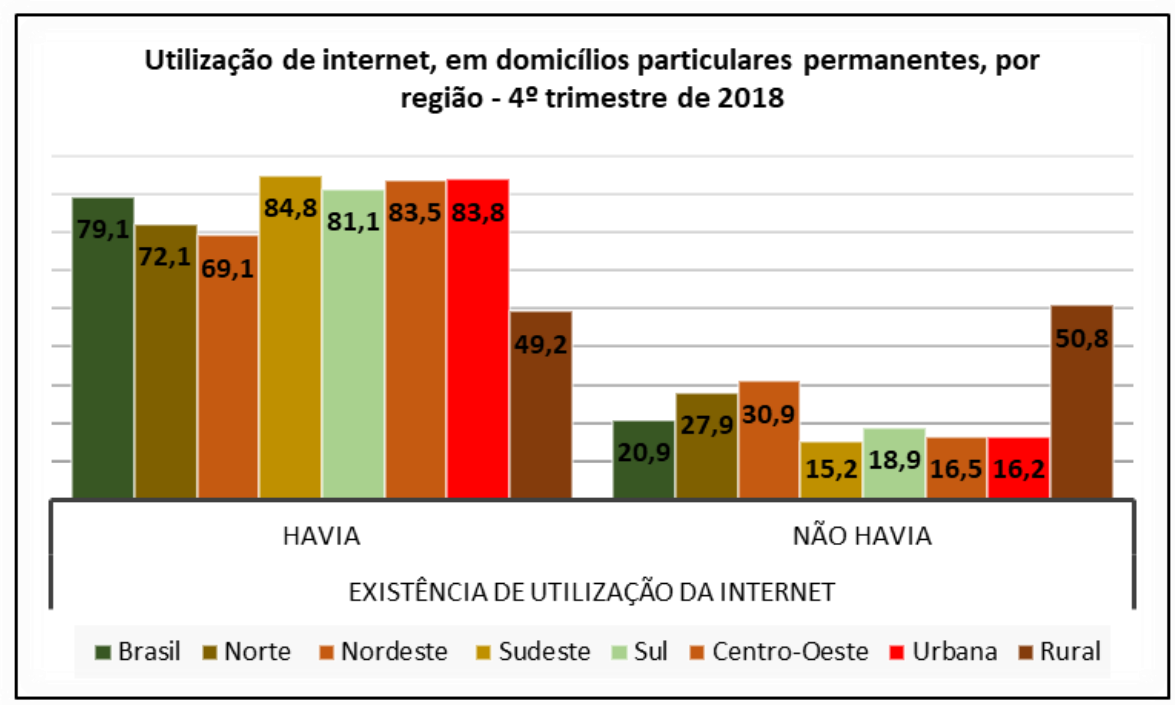

Fonte: Elaborado pelas autoras, baseadas em IBGE (2018).

O Gráfico 4 demonstra que, apesar da difusão do uso da internet, a região Nordeste é a que apresenta o menor índice de acesso, em torno de 69,1\%, inferior à média nacional, apresentando um déficit de acesso ao serviço em torno de $30,9 \%$. Por outro lado, as regiões Sudeste e Centro Oeste apresentam percentuais de acesso bastante próximos, sendo de 84,8\% e $83,5 \%$, respectivamente, maiores do que a média nacional, que é de $79,1 \%$. Ainda, constata-se que um contingente de $20,9 \%$ dos lares brasileiros, ou seja, quase $21 \%$, não têm acesso à internet.

Os dados mostram uma contradição em relação ao perfil socioeconômico dos estudantes - alegado como sendo a causa principal da paralisação das atividades das universidades da Região Sudeste - e o perfil da referida Região, de acesso à internet, que aparece no Gráfico 4.

Partindo-se da constatação da suspensão das atividades em cerca de $80 \%$ das universidades públicas federais, vejamos os dados, sob a ótica relacionada ao contingente de discentes que se encontraram com suas atividades paralisadas, esquematizados no Gráfico 5. 
Gráfico 5. Discentes com atividades suspensas, por região geográfica

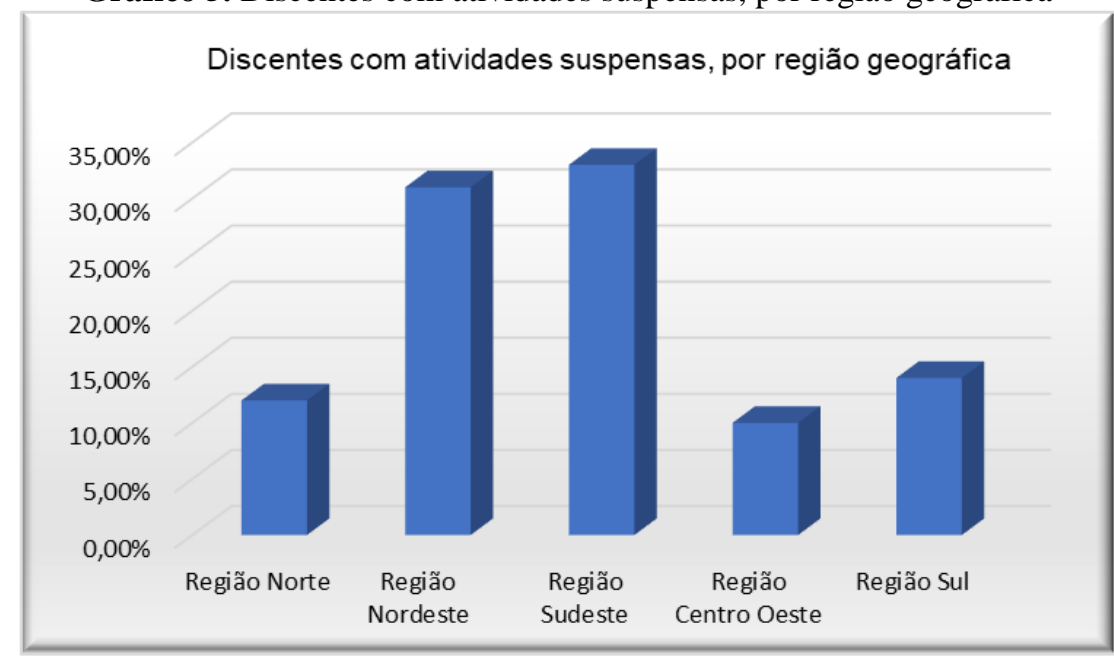

Fonte: Elaborado pelas autoras, baseadas em MEC, 2020.

A Região Sudeste apresentou o maior índice de discentes com atividades paralisadas, em torno de 33\%, muito próximo ao índice de alunos sem atividades da Região Nordeste, que é de $31 \%$. Segundo matéria assinada pela jornalista Isabela Palhares, na Folha de São Paulo(2020), 60\% das instituições da rede federal, em todo o território nacional, optaram por suspender o calendário acadêmico, alegando que mais de 70,2\% dos estudantes da rede federal veem de famílias com renda mensal per capita de até 1,5 salário mínimo, segundo dados da ANDIFES (2018).

Chama a atenção o fato de que, de acordo com dados do IBGE (2020), relativos à PNAD Contínua, e em conformidade com os dados constantes no Gráfico 4, o percentual de domicílios brasileiros, que utilizou a internet, subiu de $74,9 \%$, no ano de 2017 , para $79,1 \%$ no ano de 2018, sendo que a Região Sudeste é a que tem o maior percentual de domicílios com acesso, que é de $84,8 \%$, isto é, quase $85 \%$ dos domicílios da Região Sudeste têm acesso à internet. Tais dados levam a alguns questionamentos: por que a Região mais rica do país, que ostenta um nível de acesso à internet, superior à média nacional, foi a que mais excluiu os discentes das atividades de ensino remoto ou em regime de atividades parciais? A alegação a respeito do perfil socio econômico do aluno procede?

O que se constatou foi que não havia condições de retorno às aulas presenciais, no curto prazo, porque escolas e universidades aglomeram, e o vírus COVID-19 tem, na aglomeração de pessoas, o seu maior aliado na disseminação do contágio.

No mês de maio de 2020, foi criado, pela ANDIFES (2020, p.6) um Grupo de Trabalho (GT) com a participação de diversos especialistas em epidemiologia, edificações e gestão acadêmica, que definiu um protocolo de ações para o retorno às atividades presenciais, baseado em cinco eixos: 1) proposta de biossegurança; 2) proposição de um plano de contingência de protocolos para identificar e viabilizar possíveis atividades de ensino, pesquisa e extensão; 3) estabelecimento de cenários e meios didáticos e pedagógicos, de 
infraestruturas e epidemiológicos, para as atividades de ensino, pesquisa e extensão, no póspandemia; 4) elaboração de um Plano global de investimentos nas universidades federais, em infraestrutura física e tecnologia da informação; 5) orientações e estudos pertinentes ao enfrentamento da pandemia pelas universidades federais.

Em julho de 2020, o MEC (2020, p.4), estabeleceu um Protocolo de Biossegurança para o retorno das atividades nas Instituições Federais de Ensino, enfatizando que a transmissão da doença exige uma reorganização das estruturas tradicionais dos órgãos públicos e privados, e que o Estado, nas três esferas de sua atuação, está adotando medidas de isolamento, quarentena e distanciamento social para preservar a vida das pessoas.

Nos primeiros meses do ano de 2021, transcorrido quase um ano do início da pandemia da COVID-19, a situação sanitária, no Brasil, é a que segue sintetizada no Gráfico 6, por região geográfica, conforme dados coletados no dia 04 de fevereiro de 2021, no portal do Ministério da Saúde.

Gráfico 6. COVID-19: Casos e óbitos, por região geográfica, no Brasil.

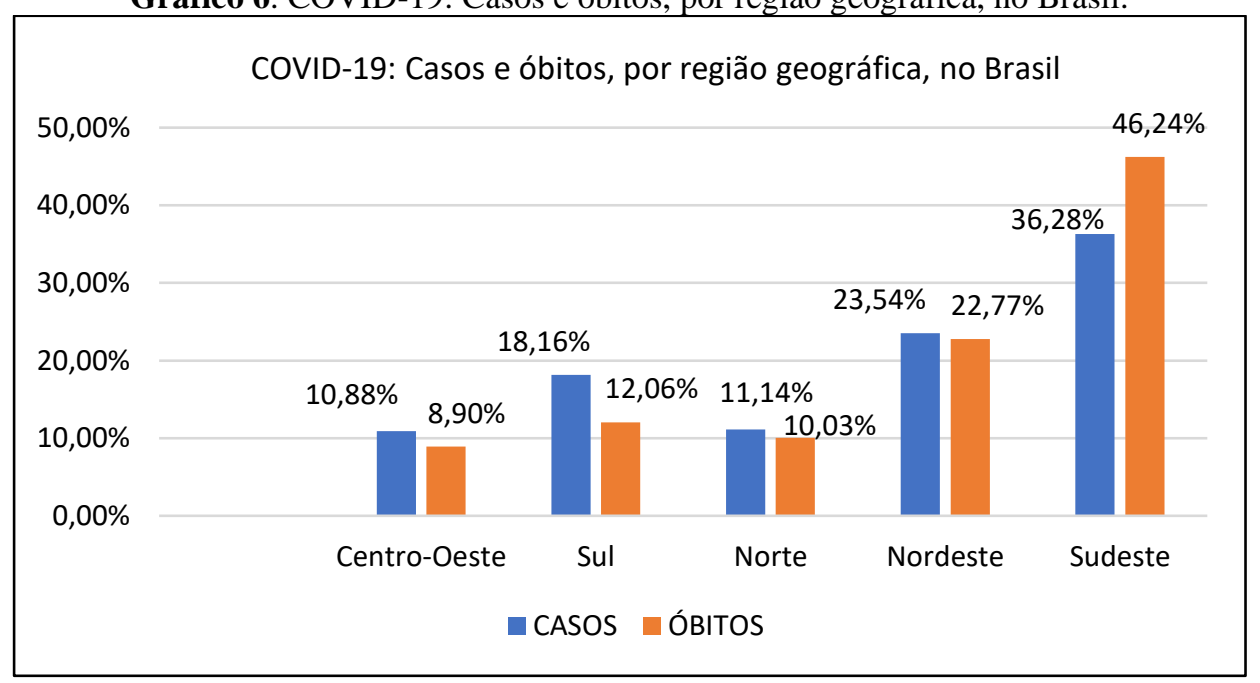

Fonte: Elaborado pelas autoras, baseados no Ministério da Saúde (2021).

As regiões Sudeste e Nordeste lideram, tanto as estatísticas relacionadas ao número de casos, como ao número de óbitos. O Ministério da Saúde, no dia 19 de janeiro de 2021, instituiu um Informe Técnico, contendo recomendações sobre a Campanha Nacional de Vacina contra a COVID-19, disponível no portal oficial do Ministério.

No início do mês de fevereiro de 2021, conforme dados disponíveis no portal do MEC (2021), no link Funcionamento das Universidades Federais, todas as 69 IFES estão ofertando seus cursos de graduação de forma remota; em relação aos cursos de pós-graduação, 63 estão oferecendo de forma remota, $4 \mathrm{em}$ regime de atividades parciais e $2 \mathrm{em}$ regime normal, e, em relação às atividades administrativas, 52 universidades federais estão em regime de trabalho remoto, 13 em regime parcial e 4 em regime normal. 


\section{Alguns dados do ensino superior à distância, no Brasil}

Somente no ano de 1996, a EaD foi reconhecida como modalidade de ensino, com a aprovação da Lei de Diretrizes e Bases da Educação Nacional (LDB), Lei n. ${ }^{\circ}$ 9394/96, de 20 de dezembro de 1996. No mesmo ano, foi criada a Secretaria de Educação a Distância (SEED), no âmbito da estrutura organizacional do Ministério da Educação. Apesar de previsto na LDB, o ensino a distância somente foi regularizado no ano de 2005, através do Decreto n. ${ }^{\circ}$ 5.622/2005, de 19 de dezembro de 2005, que regulamentou o Art. 80 da LDB, estabelecendo, através deste Decreto, as diretrizes para a oferta de educação na modalidade a distância.

De acordo com dados da Associação Brasileira de Educação a Distância - ABED (2018, p.9), dos recursos utilizados como ferramentas de aprendizagem no ensino a distância, as teleaulas vêm em primeiro lugar; vejamos este panorama, detalhado no Gráfico 7.

Gráfico 7. Ferramentas de aprendizagem inerentes ao ensino a distância

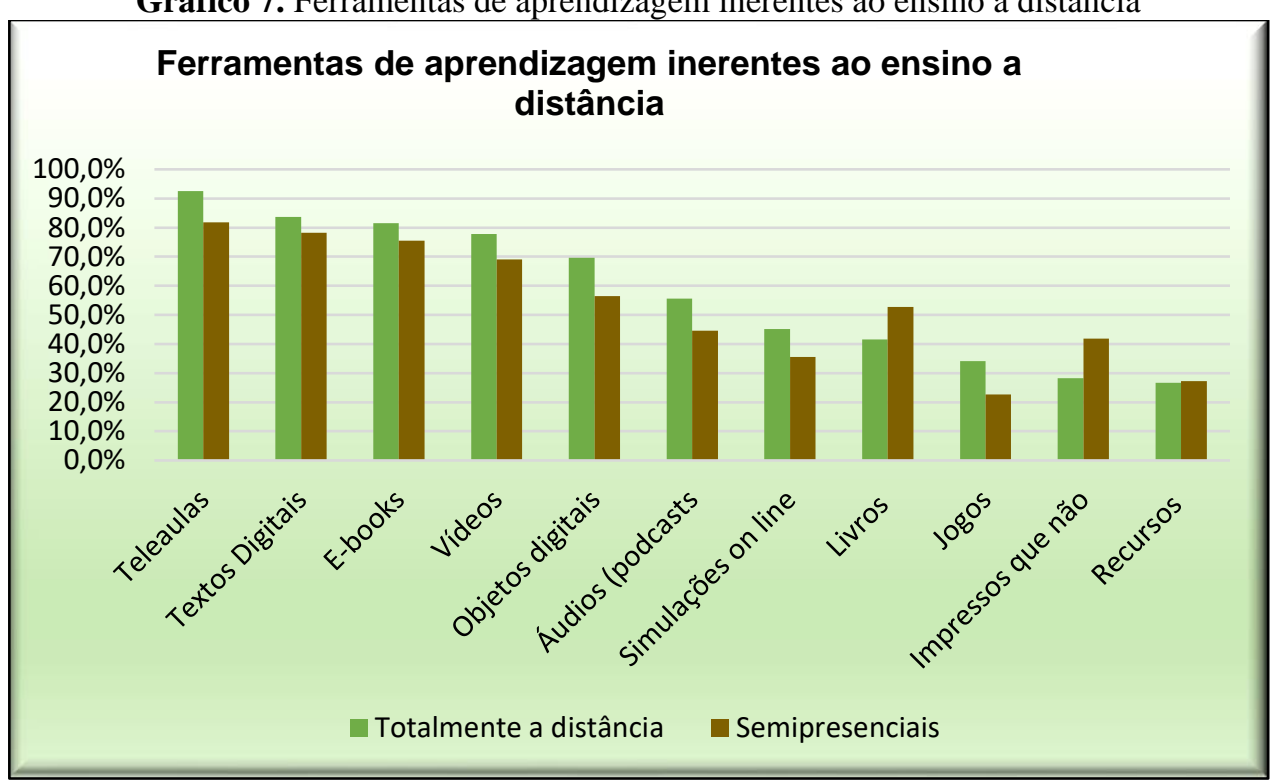

Fonte: Elaboração das autoras, baseadas em ABED (2018, p. 11).

Para a ABED (2018, p.9), as teleaulas aparecem como recurso pedagógico em primeiro lugar, devido a diversos fatores, destacando-se, neste caso, a tendência à humanização do ambiente on-line, o que considera como fator preponderante, a partir da constatação de que no nosso país, em certas regiões, o acesso a uma educação de melhor qualidade só ocorre com a ajuda da tecnologia. Sobre os textos digitais, aparecem como recurso de aprendizagem em $83,7 \%$ de cursos totalmente $\mathrm{EaD}$, e em 78,2\% em cursos semipresenciais, ressaltando que o recurso foi dos primeiros formatos do ensino presencial que se adaptou ao ambiente digital, pois exige pouca habilidade técnica e ocupa menos espaço e banda. 
Conforme dados da ABED (2018, p.9), o terceiro recurso pedagógico do ensino a distância são os e-books, que aparecem com 81,5\% e 75,5\%, em cursos totalmente a distância e em cursos semipresenciais, respectivamente. Os vídeos, que não sejam do estilo de teleaulas, são o recurso pedagógico que aparece como quarto colocado, respondendo por um percentual de $77,8 \%$, nos cursos totalmente a distância, e $69,1 \%$ nos cursos semipresenciais. A $\operatorname{ABED}(2018$, p.10) registra que os objetos digitais de aprendizagem, que permitem que se criem aulas dinâmicas, é o quinto recurso pedagógico que aparece nas estatísticas do Censo de 2018.

Já os livros impressos têm registrado queda, como recurso didático na modalidade $\mathrm{EaD}$, sendo substituídos por recursos mais sofisticados, como podcasts, por exemplo, sendo, no entanto, um recurso pedagógico que aparece mais em cursos semipresenciais. A ABED (2018, p.10) ressalta que os jogos eletrônicos favorecem a aquisição de habilidades mais complexas - enquanto recurso pedagógico - tais como a aquisição de pensamento estratégico, capacidade de planejamento e visão colaborativa, ferramentas importantes para a educação deste século XXI; em relação aos recursos adaptativos, ainda estão em fase de desenvolvimento. "Outros recursos que despontam no cenário internacional incluem a inteligência artificial, a realidade virtual e aumentada (chamada de realidade mista), a blockchain e os assistentes virtuais" (ABED, 2018, p.10).

É preciso esclarecer que o ensino semipresencial oferece apenas uma parte do curso na modalidade presencial, podendo ter sua origem em cursos presenciais ou em cursos a distância, sendo que quando são originários de cursos presenciais, nem todas as disciplinas são ofertadas na modalidade presencial e os encontros presenciais ocorrem na própria instituição de ensino. Já os semipresenciais originários de cursos $\mathrm{EaD}$, necessitam de um polo de apoio presencial, para os encontros presenciais, e precisa atender a algumas especificidades, de acordo com a $\operatorname{ABED}(2018$, p.70): os conteúdos curriculares têm que estar corretos e atualizados, sendo necessário que os tutores e docentes sejam qualificados e as metodologias devem ser eficazes no processo de aprendizagem.

\section{Uma nova instituição para um novo tempo}

Dourado (2019, p.14-15) lembra que entre os muitos deveres do Estado, destaca-se o do estabelecimento do Plano Nacional de Educação (PNE), de vigência decenal, que tem o objetivo de estabelecer diretrizes, objetivos, metas e estratégias, visando a manutenção e o desenvolvimento do ensino, em seus diversos níveis, etapas e modalidades, o que, o atual governo federal questiona, inclusive, reduzindo os recursos destinados à educação. Tais questionamentos, somados aos relacionados ao conhecimento científico e referentes ao papel e às restrições à autonomia universitária - concretizadas em forma de decretos, cortes orçamentários e proposta de nova governança/projeto Future-se - colocam em risco o pluralismo de ideias e de concepções pedagógicas, a autonomia didático-científica, administrativa e de gestão financeira e patrimonial, entre tantas outras conquistas asseguradas pela Constituição Federal de 1988. 
É nesse cenário que se situam os desafios para a educação nacional no que concerne à garantia de acesso e permanência com qualidade social, num estado com enorme dívida social no campo educacional e que apresenta riscos no tocante à manutenção do Estado Democrático de Direito, como preconizado na Constituição Federal de 1988 (DOURADO, 2019, p.13).

A Meta 12 do PNE para o decênio 2014/2024 é elevar a taxa bruta de matrícula na educação superior para 50\%(cinquenta por cento), e a taxa líquida para 33\% (trinta e três por cento), da população de 18(dezoito) a 24 (vinte e quatro) anos, assegurada a qualidade da oferta e expansão para, pelo menos, $40 \%$ (quarenta por cento) das novas matrículas no segmento público. (INEP, 2015, p. 209). Pelos dados analisados, constatou-se que persiste a desigualdade, histórica, no acesso à educação superior, entre as diferentes regiões geográficas de nosso país, entre os diferentes grupos populacionais e entre os diferentes estratos socioeconômicos.

Este é um grande desafio para as universidades federais e para o Estado, levando-se em consideração que o ano de 2020 será lembrado como o ano em que as universidades federais viveram a pior crise de que se tem notícia, neste início do século XXI, cuja face mais cruel foi a constatação do despreparo de todos (Estado e universidades federais), expondo a necessidade de apoio, diálogo e cooperação, entre todos os envolvidos, o que, infelizmente, ainda está em construção.

Boaventura de Sousa Santos (2018, p. 588-592), faz reflexões complexas a respeito da ideia da universidade moderna, referindo-se a uma mudança de paradigma, afirmando, entre outras coisas, que a universidade será, em breve, uma instituição do passado e, que, para ser capaz de se pautar pela ciência moderna, deverá transformar os seus processos de investigação, de ensino e de extensão, e, neste sentido, para ele o verdadeiro mercado para o saber universitário, reside no futuro, com o que estamos plenamente de acordo. Segundo o autor,

O grande perigo para a universidade nas próximas décadas é o de os dirigentes universitários se limitarem a liderar inércias. As grandes transformações não podem ser postas de parte só porque a universidade criou a seu respeito o mito da irreformalidade. É de prever que a curto prazo a crise institucional monopolize o esforço reformista (SANTOS, 2018, p.592).

A universidade pública deverá, no dizer de Ristoff (2020), assumir papel de liderança em relação ao enfrentamento dos desafios da atualidade, referentes à segurança alimentar, mudanças climáticas e saúde pública, entre outros, cabendo ao Estado investir fortemente para viabilizar tais ações, lembrando, ainda, que o conhecimento, necessita, para avançar, de investimento público, decisivo e continuado e, para o autor, o campus do futuro não será um lugar, mas uma rede, que fará parte de inúmeras outras redes já espalhadas mundo afora. 


\section{Considerações Finais}

Diante das medidas tomadas pelo Estado, em relação à educação superior, foi perceptível a inércia e a incapacidade em fornecer respostas assertivas e em estabelecer rotinas e procedimentos padronizados, que fossem capazes de evitar que quase um milhão de estudantes, matriculados nas universidades federais, ficassem com suas atividades acadêmicas paralisadas. O fato de, a cada trinta dias, o MEC emitir Portarias que prorrogavam o prazo da situação de excepcionalidade, provocou inseguranças diversas, relacionadas, principalmente, a um futuro difícil de ser previsto e planejado, pois faltavam normativas legais que assegurassem a uns e outros, respaldo e capacidade de planejamento, para o período de vácuo imposto pela suspensão das atividades presenciais.

Os conflitos foram inevitáveis e a inércia foi o resultado da negação, da falta de diálogo entre as partes envolvidas e da incapacidade de todos, em lidar com a calamidade, processo agravado pela ausência de lideranças capazes de mobilizar esforços conjuntos para o enfrentamento da situação. A cegueira causada pelas intermináveis discussões ideológicas serviu, a uns e outros, como desculpa para a omissão e para a ausência de propostas de soluções viáveis diante da gravidade da situação. Todos perdem, as crises se aprofundam, deixando vulneráveis os entes sociais envolvidos e, neste processo permeado por diversas crises de identidade e de autonomia, a opinião pública julga e as (des)informações se propagam, em progressão geométrica, à semelhança do vírus. A quem serve tal tipo de coisa? Sabe-se que as universidades federais têm, no convívio harmônico da diversidade de pensamentos, de orientações filosóficas e da pluralidade de ideias, um de seus traços mais marcantes, o que acaba por replicar as relações contraditórias e conflituosas próprias de ambientes multiculturais. Tal peculiaridade no ambiente universitário, por um lado, aproxima culturas, pessoas, visões e comportamentos, e, por outro, torna o ambiente extremamente desafiador, cheio de contradições e resistência, de forma que o ensino presencial está vivenciando uma crise de identidade, e uma grande contradição na medida em que, mesmo que os dados tenham apontado para uma alarmante exclusão digital e tecnológica, no primeiro semestre de 2020, dos discentes das universidades federais, em torno de 77,40\%, é impossível ignorar a existência de ferramentas e plataformas interativas nos meios digitais, adequadas à viabilização do ensino a distância, tais como o Skype, Zoom Cloud Meetings, Hangouts Meet, Cisco Webex, Moodle, e a mais rudimentar de todas, o e-mail, passando pelas interações favorecidas pelas redes sociais, como o WhatsApp.

Isto posto, pergunta-se: por que apesar dos recursos investidos no sistema Universidade Aberta do Brasil (UAB), as universidades federais se mostraram incapazes de adotar a educação a distância, excluindo quase um milhão de estudantes, em todo o país, das atividades de ensino? Que dificuldade há em se adotar as teleaulas, pelo menos durante a pandemia? Qual a justificativa para não se disponibilizar, por e-mail, capítulos de livros e outros materiais didáticos, em formato digital? Por que não utilizar o youtube como plataforma digital, disponibilizando vídeos didático pedagógicos? O que impede as universidades federais de elaborarem plataformas de simulações on-line, destinadas ao 
aprendizado remoto? Por que não usar as simulações dos jogos eletrônicos, como recurso pedagógico, no ensino remoto?

Diante de tantos questionamentos, temos algumas hipóteses. Constatamos que as universidades, com suas estruturas extremamente hierarquizadas, tornaram-se instituições com alguma dificuldade em planejar, por isso, também lhes falta o preparo para administrar riscos ou calamidades, situação que se agrava devido ao modelo organizacional em que se encontram fundamentadas, marcado por uma pesada burocracia e pela submissão à regramentos jurídicos por sua vez, mais rígidos e inflexíveis que os que criaram, através de seus colegiados e inúmeras estruturas características do modelo atual de universidade pública federal. Aliás, a dificuldade em administrar calamidades estende-se também ao Estado, e, em particular, ao MEC, que não estabeleceu, até o momento, um protocolo de procedimentos que possa ser utilizado por todas as universidades federais e institutos que integram o ensino superior público.

Além do mais, sabe-se que o ensino remoto é mais desafiador para o docente, inclusive, porque não é possível replicar os horários do ensino presencial, na modalidade $\mathrm{EaD}$. A dinâmica de aprendizado é mais complexa, e tal novidade causa, primeiro, resistência, e, em seguida, a negação, porque, o que ocorre é que os docentes, em sua grande maioria, têm pouca intimidade com as TICs, necessitando, portanto, de capacitação. Entretanto, é mais fácil criticar, opor resistência e apontar dificuldades, do que propor soluções concretas.

Pelos dados desta pesquisa, percebe-se que o ensino remoto não é tão difícil de ser implementado, bastando uma certa boa vontade dos entes envolvidos, e a abertura de créditos específicos, por parte do Estado, destinados à modernização dos parques tecnológicos das universidades federais. Quer se queira ou não, o futuro das universidades federais será adotar um modelo de ensino mediado pela tecnologia, sendo capaz, ela própria de se transformar em uma nova instituição, para um novo tempo, no período pós-pandemia. As ferramentas para tal processo já existem há algum tempo, necessitando, para serem implementadas, do estabelecimento de um diálogo entre o Estado e as universidades públicas, visando a sobrevivência do patrimônio educacional das universidades federais, diálogo este que, infelizmente, encontra-se estagnado, por diversos motivos.

Nada mais será como antes. Os paradigmas, as crenças, os dogmas, a educação, a saúde pública, a economia, as relações de trabalho, as interações e subjetividades próprias das relações pessoais, as políticas de Estado, bem como as consequências e os impactos impostos pelo isolamento social, foram a causa de um cruel choque de realidade, que expôs toda a fragilidade do ser humano e das instituições que se acreditava inabaláveis.

\section{Referências}

ABED. Censo EAD.BR 2018/2019: Relatório analítico de aprendizagem a distância no Brasil. São Paulo: ABED, 2018. 
ANDIFES. Propostas sobre Biossegurança, Contingências, Meios Pedagógicos e Infraestruturas para as atividades de ensino, pesquisa e extensão, decorrentes da pandemia. Brasília: ANDIFES, 2020. Disponível em: <http://www.andifes.org.br/wp-content/uploads/2020/09/O-documento-pode-serconferido-na-\%C3\%ADntegra-aqui.pdf>. Acesso em: 05 jan. 2021.

ANDIFES. V Pesquisa Nacional de Perfil Socioeconômico e Cultural dos(as) Graduandos(as) das IFES 2018. Uberlândia: UFU, 2018. Disponível em: <http://www.andifes.org.br/wp-content/uploads/2019/05/VPesquisa-do-Perfil-Socioecon\%C3\%B4mico-dos-Estudantes-de-Gradua\%C3\%A7\%C3\%A3o-dasUniversidades-Federais-1.pdf>. Acesso em: 19 maio 2020.

BRASIL. Casa Civil. Legislação Covid-19. Brasília: 2020. Disponível em: <http://www.planalto.gov.br/CCIVIL_03/Portaria/quadro_portaria.htm>. Acesso em: 27 maio. 2020.

DOURADO, Luiz Fernandes. Estado, Educação e Democracia no Brasil: retrocessos e resistências. Educação \& Sociedade, Campinas, v. $\quad 40, \quad 2019 . \quad$ Disponível <http://www.scielo.br/scielo.php?script=sci_arttext\&pid=S010173302019000100203\&lng=en\&nrm=iso>. Acesso em: 26 maio 2020.

FERRARI, Andrés; CUNHA, André Moreira. A pandemia do Covid-19 e o isolamento social: saúde versus economia. 20 de março de 2020. Disponível em: <https://www.ufrgs.br/fce/a-pandemia-do-covid-19-e-oisolamento-social-saude-versus-economia/\#_ftnref5>. Acesso em: 25 maio 2020.

PALHARES, Isabela. $60 \%$ das universidades federais rejeitam ensino a distância durante quarentena: instituições dizem não conseguir garantir qualidade de acesso a todos os alunos. Folha de São Paulo. São Paulo: 31 mar. 2020. Disponível em: <https://www1.folha.uol.com.br/educacao/2020/03/60-universidadesfederais-rejeitam-ensino-a-distancia-durante-quarentena.shtml>. Acesso em: 16 maio 2020.

INEP. Plano Nacional de Educação PNE 2014-2024: Linha de Base. Brasília: INEP, 2015.

IPEA. Instituto de Pesquisa Econômica Aplicada. Estudo mostra desenvolvimento humano nas macrorregiões $\quad$ brasileiras. $2016 . \quad$ Disponível <https://www.ipea.gov.br/portal/index.php?option=com_content\&view=article\&id=27463>. Acesso em: 19 maio 2020.

MINISTÉRIO DA EDUCAÇÃO. MEC. Coronavírus: monitoramento das instituições de ensino. 2020. Disponível em: 〈http://portal.mec.gov.br/coronavirus>. Acesso em: 19 maio 2020.

MINISTÉRIO DA EDUCAÇÃO. MEC. Educação Superior a Distância. 2020. Disponível em: <http://portal.mec.gov.br/instituicoes-credenciadas/educacao-superior-a-distancia>. Acesso em: 29 maio 2020.

MINISTÉRIO DA EDUCAÇÃO. MEC. Lei $\mathbf{n}^{\circ}$ 9.394, de 10 de dezembro de 1996. Disponível em: <http://portal.mec.gov.br/seesp/arquivos/pdf/lei9394_ldbn1.pdf>. Acesso em: 01 jun. 2020.

MINISTÉRIO DA EDUCAÇÃO. MEC. Protocolo de Biossegurança para retorno das atividades nas Instituições Federais de Ensino. Brasília: MEC/SESu, 2020. Disponível em: <http://portal.mec.gov.br/coronavirus>. Acesso em: 04 fev. 2021.

MINISTÉRIO DA SAÚDE. Painel Coronavirus. Disponível em: <https://covid.saude.gov.br/>. Acesso em: 04 fev. 2021.

MINISTÉRIO DA SAÚDE. Secretaria de Vigilância em Saúde. Coordenação Geral do Programa Nacional de Imunizações. Informe Técnico: Campanha Nacional de Vacinação contra a COVID-19. Disponível em: <https://www.conasems.org.br/wp-content/uploads/2021/01//nforme_Tecnico_Vacina_COVID-19.pdf>. Acesso em: 04 fev. 2021.

RISTOFF, Dilvo. A caminho da nuvem: impactos da pandemia na educação. 2020. Disponível em: <https://www.educa2022.com/post/a-caminho-da-nuvem-impactos-da-pandemia-naeduca\%C3\%A7\%C3\%A3o>. Acesso em: 01 jun. 2020. 
SANTOS, Boaventura de Sousa. Construindo as Epistemologias do Sul: Antologia essencial. Volume I. Para um pensamento alternativo de alternativas Buenos Aires: CLACSO, 2018. Disponível em: <http://biblioteca.clacso.edu.ar/clacso/se/20181203044407/Antologia_Boaventura_PT1.pdf >. Acesso em: 10 maio 2020.

\section{Correspondência}

Maria das Graças Gonçalves Vieira Guerra: Doutora em Educação (UFPB-2007), Pós-Doutora pela Universidade do Porto - Portugal (2019), Mestre em Administração (UFPB-2003) e Licenciada em Pedagogia (UNIGRAN-EaD-2012). É Professora Associada III do Centro de Educação da Universidade Federal da Paraíba, Professora dos quadros permanentes dos Programas de Pós-Graduação em Educação (PPGE) e de Políticas Públicas, Gestão e Avaliação da Educação Superior (MPPGAV) da UFPB.

E-mail: gracinhavieira@yahoo.com.br

Orcid: http://orcid.org/0000-0002-6943-0338

Lourdes Maria Rodrigues Cavalcanti: Doutoranda pelo Programa de Pós-Graduação em Educação (PPGE) e Mestre em Políticas Públicas, Gestão e Avaliação da Educação Superior (MPPGAV-2019) pela Universidade Federal da Paraíba (UFPB).

E-mail: lourdesrcavalcanti@gmail.com

Orcid: https://orcid.org/0000-0002-1659-0821

Texto publicado em Currículo sem Fronteiras com autorização dos autores. 